\title{
RESEARCH
}

\section{Exploring How Postmillennial Pharmacy Students Balance Life Priorities and Avoid Situations Known to Deplete Resilience}

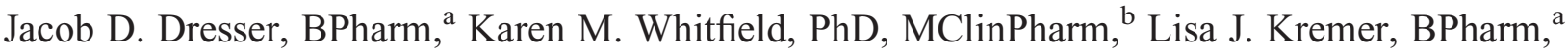 \\ Kyle J. Wilby, PharmD, PhD, BSP \\ ${ }^{\text {a }}$ University of Otago, School of Pharmacy, Aotearoa, New Zealand \\ ${ }^{b}$ The University of Queensland, School of Pharmacy, Queensland, Australia \\ Submitted August 26, 2020; accepted January 5, 2021; published April 2021.
}

Objective. Students are facing increasing academic pressures that can contribute to poor wellbeing. Evidence to inform the development of better student support services is weak. This study aimed to explore Bachelor of Pharmacy students' self-reported life priorities and ways they strategize to avoid resilience-depleting events on a day-to-day basis.

Methods. Postmillennial (those born after 1996) pharmacy students enrolled in their final year of pharmacy school were introduced to the coaching concepts of the Wheel of Life and anti-goals. Students' top eight life priorities were collected and categorized. Students were asked to submit one anti-goal targeting a strategy used to avoid resilience depletion. Anti-goals were coded according to student priority areas and overarching themes were interpreted.

Results. The top priorities of 110 final-year pharmacy students were: family, finance, health, friends/ relationships, study, career prospects, fitness, personal growth, travel, and mental health/wellbeing. Priorities were both similar and dissimilar to traditional coaching priorities. Sixty-eight anti-goals were coded. The themes "being prepared" and "being present" were used to summarize strategies that students employed to avoid resilience depletion.

Conclusion. The life priorities of newer student generations may be changing to be more individualistic and include a greater focus on self-help, while maintaining the core priorities of family, health, and finance. These findings uphold the notion that student support mechanisms must be modernized to accommodate students' needs.

Keywords: coaching, resilience, wellbeing, education

\section{INTRODUCTION}

Health professional students are facing greater academic and non-academic pressures with increasing stress levels that deplete resilience and negatively impact wellbeing. ${ }^{1-9}$ Whether it is coursework, family expectations, financial struggles, lack of time for self-care or socialization, or other factors, the ability of students to achieve balance in their lives is constantly challenged. ${ }^{1,5,10}$ The consequences of negative impacts may include, poorer academic performance, increases in student withdrawals or program deferrals, and/or decompensation of students' mental health and wellbeing. ${ }^{1,6-8,11-14}$ These consequences may be detrimental not only for students but also for program administration and sustainability. It is therefore

Corresponding Author: Kyle J. Wilby, Dalhousie University, College of Pharmacy, 5968 College St., Halifax NS, B3H 1X7, Canada. Tel: 902-494-2378. Email:

kyle.wilby@dal.ca important for training programs to be aware of student priorities in times of hardship and to provide students with the necessary skills and abilities to build resilience, improve wellbeing, and achieve overall life balance.

Student stress has been correlated with decreased quality of life and mental health consequences. Hirsch and colleagues demonstrated that the mean mental component summary scores of preclinical pharmacy students (prior to experiential training) on the 36-Item Short Form Health Survey (SF-36) was significantly lower than the average for US pharmacy students as a whole. ${ }^{11}$ Furthermore, lower mental component summary scores were strongly associated with greater Perceived Stress Scale (PSS) scores and maladaptive strategies to cope with stress. Marshall and colleagues demonstrated a significant negative correlation between stress and mental health using the 12-Item Short Form Health Survey (SF-12). ${ }^{1}$ Silva and Figueiredo-Braga investigated stress, anxiety, and depressive symptoms in students undergoing an 


\section{American Journal of Pharmaceutical Education 2021; 85 (4) Article 8369.}

Integrated Master's in Pharmaceutical Sciences program. ${ }^{13}$ Findings showed a significant positive correlation between greater Hospital Anxiety and Depression Scale (HADS) subscale scores with greater Perceived Stress Scale (PSS) scores, and a significant negative correlation with academic satisfaction and happiness. Sabourin and colleagues reported on mental health in PharmD students using the Counselling Center Assessment of Psychological Symptoms-62 (CCAPS-62). ${ }^{14}$ They found that greater than $25 \%$ of students scored in the high severity range for depression, generalized anxiety, academic distress, and eating concerns subscales. The findings from these studies demonstrate that not only is student stress a problem, it also negatively affects health beyond academic considerations.

Programs have a responsibility to provide adequate support services and training for students to learn coping skills and stress management given the high student stress levels and associated decline in mental health and wellbeing. Despite calls for increased use of these services, little data are available to guide improvement, especially in the era of newer post-millennial generations (those born after 1996). Most literature, to date, primarily focuses on student satisfaction with these services, which appears to be low. ${ }^{15}$ Conclusions from other studies refer to providing increased awareness of service availability, ${ }^{11}$ increases in the amount and types of professional services (eg, counselling), ${ }^{1}$ and use of curricular-embedded interventions. ${ }^{16}$ To provide better support to newer generations, services need to be modeled to prioritize issues that are of importance to them moving forward.

Given the negative implications of student stress on their mental health and wellbeing and the important role of student support mechanisms offered by schools, it is necessary to explore priorities for students outside of academia alone. The objectives of this study were to determine students' priority areas for life-balance and to identify specific strategies students use to avoid situations they perceive will deplete their resilience.

\section{METHODS}

This was an exploratory study conducted within a professional skills laboratory session. When the survey was conducted in 2020, students were enrolled in their final year (fourth year) of the Bachelor of Pharmacy (BPharm) program at the University of Otago in Dunedin, Aotearoa New Zealand. Pharmacy students are typically aged 21-25 years; thus, some participants represented the millennial generation while others represented the postmillennial generation. Graduates from this program are required to complete a one-year internship within a practice environment before registering as a pharmacist.
Previous to this laboratory session, students had completed experiential training placements in community, hospital, and rural pharmacy settings. All students who attended the skills laboratory were eligible to participate. Departmental approval to conduct this project was provided and full ethical review was exempted.

Students completed two activities during the skills laboratory. First, an instructor introduced the concept of the Wheel of Life as a means to determine students' overall lifebalance and then provided a personal example. The Wheel of Life is well-known in coaching programs and aims to have participants identify life priority areas and self-assess their perceived satisfaction with each priority. ${ }^{17}$ Students were provided a paper-based template and instructed to brainstorm their top eight life priorities to place around the spokes of the Wheel of Life. A list of sample priorities was provided, but students were encouraged to personalize their list. Upon plotting their top eight priorities on the template, students were asked to rate their satisfaction with their achievement of each priority on a scale of 1 to 10 . Students then connected the plotted numbers to receive a visual representation of their Wheel of Life. Upon completion of the exercise, students were asked to anonymously write their top eight priorities on a separate sheet of paper (without ratings) and hand these in to be used in this study.

Second, an instructor introduced the concept of antigoals to students as a way to organize their day so that they would be able to avoid resilience-depleting situations and negative impacts on their wellbeing. ${ }^{18}$ Anti-goals are defined as undesirable states to be avoided. The use of anti-goals aims to help people design their best possible days by identifying and focusing on the things that they dislike the most. For example, one may create an antigoal of "never miss having my morning coffee by leaving the house no later than 8:00 AM" or "rarely eat unhealthy food by meal prepping my lunches every weekend." For this study, students were asked to think about their "worst possible day" and generate anti-goals matching each component. Upon completion of the exercise, half of the students (those attending morning sessions) were anonymously asked (if they felt comfortable doing so) to submit at least one anti-goal on a separate sheet of paper.

To investigate students' overall priorities for achieving life-balance, data from the Wheel of Life exercise were extracted into an Excel spreadsheet. Student priorities were reviewed by one investigator and coded according to similar meaning. For example, priorities that included the words "running," "exercise," and/or "gym," were categorized as "fitness." If some priorities overlapped with others (eg, applied to fitness and hobbies) but both were mentioned by multiple participants, the priority areas were kept separate. Coding continued until a final list of categories containing all 


\section{American Journal of Pharmaceutical Education 2021; 85 (4) Article 8369.}

of the priorities provided by the students was generated. A second investigator reviewed this data and discussed any discrepancies with the coding investigator. Once the final categories were stable, the proportion of students who listed each category as a priority area was determined and descriptive statistics were used to summarize results.

To investigate students' strategies to avoid resilience depletion, data from the anti-goal exercise was typed into a Word document. Anti-goals were then reviewed and deductively coded according to the priority categories identified from the Wheel of Life activity. Anti-goals that did not fit a priority category were coded as "other." The proportion of anti-goals coded for each priority category was calculated. Within each category, anti-goals were inductively coded by two investigators independently. Investigators then met to review coded data and interpret overarching themes, if present. ${ }^{19}$ Final themes were agreed upon by all investigators.

\section{RESULTS}

One hundred ten students completed the skills laboratory activities in 2020. All participants were born after 1996 and had a median age of 22 years. Approximately
$66 \%$ of students were female. Eighteen life priority categories were identified across all student responses. The majority of students (88\%) listed eight priorities. After categorization, 27 students had at least two priority areas collapsed into one overarching category based on similarity. A list of each priority and the proportion of students who identified each as a priority according to their own Wheel of Life is provided in Table 1. Although related, some categories were kept separate in situations where a large proportion of students identified both as priorities (eg, health vs mental health/wellbeing). Friends and relationships were categorized together because of the researchers inability to differentiate between the two. An "other" category captured priority categories mentioned by less than $10 \%$ of participants. When compared to the traditional Wheel of Life, priorities appeared to be modernized for newer generations. Specifically, friends/relationships, study, career prospects, personal growth, and fitness were labeled as new separate categories. A visual representation of the traditional categories paired with findings from this study is provided in Figure 1.

A total of 68 anti-goals were listed by 46 students. Anti-goals were only sought from half of the students

Table 1. Priority Areas and Associated Anti-goals Identified by New Zealand Bachelor of Pharmacy Students

\begin{tabular}{|c|c|c|c|}
\hline Life Priority & $\begin{array}{l}\text { Students } \\
(\mathrm{N}=110), \\
\text { No. }(\%)\end{array}$ & $\begin{array}{c}\text { Anti-goals } \\
(\mathbf{N}=68), \\
\text { No. }(\%)\end{array}$ & Anti-goal Example Provided \\
\hline Family & $93(84.5)$ & $2(2.94)$ & $\begin{array}{l}\text { "Don't prioritise anything else at night and call her even for a } \\
\text { few minutes to catch up on her day and wish her a good night." }\end{array}$ \\
\hline Finance & $84(76.4)$ & $5(7.35)$ & "Not go over budget for groceries." \\
\hline Health & $84(76.4)$ & $1(1.47)$ & $\begin{array}{l}\text { "Keep water bottle with me and aim to re-fill at least } 1-2 \text { times } \\
\text { per day." }\end{array}$ \\
\hline Friends/relationships & $76(69.1)$ & $2(2.94)$ & "Socialise with friends every day" \\
\hline Study & $69(62.7)$ & $9(13.2)$ & $\begin{array}{l}\text { "Be able to keep up in class, hence always do prep workshop } \\
\text { exercise and go to all the lectures." }\end{array}$ \\
\hline Career prospects & $64(58.2)$ & $0(0)$ & - \\
\hline Fitness & $59(53.6)$ & $6(8.82)$ & "Prioritise the gym four times a week." \\
\hline Personal growth & $41(37.3)$ & $0(0)$ & - \\
\hline Travel & $38(34.5)$ & $0(0)$ & - \\
\hline Mental Health/Well-being & $28(25.5)$ & $0(0)$ & - \\
\hline Social life & $28(25.5)$ & $0(0)$ & - \\
\hline Spirituality & $27(24.5)$ & $0(0)$ & - \\
\hline Hobbies & $24(21.8)$ & $0(0)$ & - \\
\hline Eating well & $20(18.2)$ & $6(8.82)$ & $\begin{array}{l}\text { "Pre-pack lunches the night before, and do large weekly shops } \\
\text { and pre-plan meals" }\end{array}$ \\
\hline Current job & 20 (18.2) & $0(0)$ & - \\
\hline Sleep & $19(17.3)$ & $22(32.3)$ & $\begin{array}{l}\text { "Avoid being tired in the morning by sleeping early the night } \\
\text { before. Set a time to do so eg, 10:30-11PM." }\end{array}$ \\
\hline $\begin{array}{l}\text { Other (pets, skincare, social media, } \\
\text { organization, lifestyle/culture) }\end{array}$ & $14(12.7)$ & $15(22.1)$ & "Keep a calendar and note down all important upcoming dates." \\
\hline House/car/other assets & $5(4.55)$ & $0(0)$ & - \\
\hline
\end{tabular}




\section{American Journal of Pharmaceutical Education 2021; 85 (4) Article 8369.}
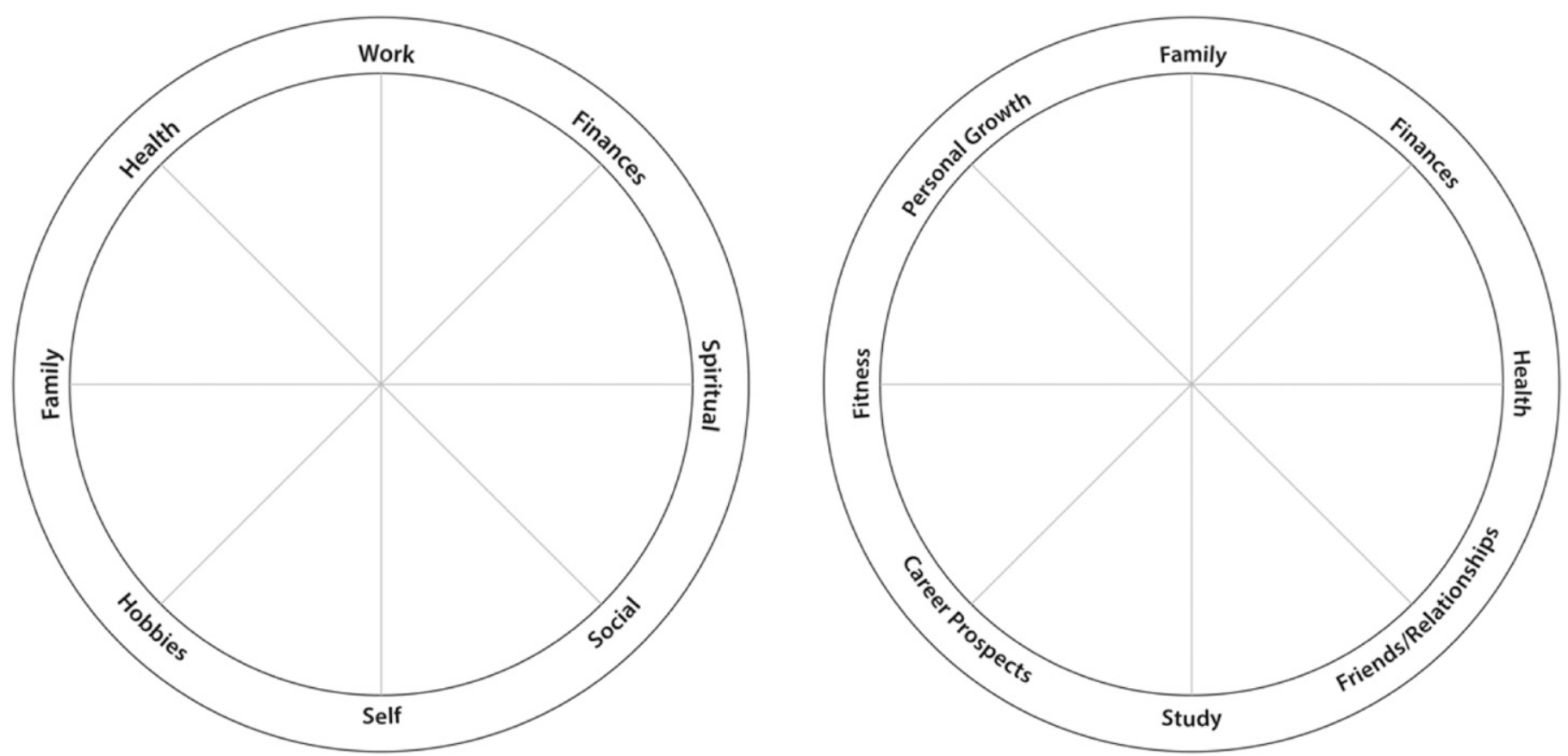

Figure 1. Comparison of Wheel of Life priorities. Top eight Wheel of Life priorities as listed by Byrne (left) ${ }^{17}$ compared to top eight priority areas identified in the study sample (right).

$(\mathrm{n}=46)$, resulting in a response rate of $84 \%$. In general, anti-goals provided insight into how students would avoid resilience-depleting situations in daily activities. The percentage of anti-goals set that related to a given priority and an example of an anti-goal for each category are provided in Table 1. As life priority areas were more overarching, many anti-goals $(22.1 \%)$ could not be categorized according to priority categories but were instead categorized as "other." Ten (14.7\%) anti-goals categorized as "other" were related to time management and/or organization.

To search for patterns and themes, the anti-goals within each category were inductively coded. Two themes were identified. According to students' anti-goals, resilience depletion could be avoided by being present and being prepared. With respect to being present, students sought to maintain daily contact with family, arrange frequent social interactions, and prioritize daily exercise. With respect to being prepared, students endeavored to prepare budgets, develop better study habits, use meal prepping as a way to eat healthy, and improve organization/time management by using alarms, reminders, or other means. Examples of the anti-goals that students listed that support each of these themes are provided in Table 1.

\section{DISCUSSION}

The purpose of this study was to explore students' self-reported life priorities and the ways in which they strategized to avoid resilience-depleting events on a dayto-day basis. Student priority areas were broad and overarching, with some alignment with traditional priorities found in the coaching literature. The priorities identified by this study, however, appeared to be modernized for a newer generation and reflected current societal trends, such as personal growth and mental health/ wellbeing. Students' strategies to avoid resilience-depleting situations were largely related to being better prepared for daily activities and/or being present for activities that aligned with their priority areas. These findings can inform student support mechanisms developed by institutions, as discussed below.

The three most frequently reported life priorities were family, finance, and health. These priority areas aligned with the traditional Wheel of Life proposed by Byrne. ${ }^{17}$ This finding may suggest that, irrespective of current living status, these priorities transcend different generations. An interesting finding, however, was that the other top-rated priority areas (specifically, career and study) differed from the traditional priorities, which may reflect generational change. Career prospects and study would likely be life priorities more specific to students. University of Otago pharmacy students graduate following the completion of their fourth undergraduate year, then undertake a pharmacy internship the following year before becoming a registered pharmacist. As internships are paid employee positions and registration is a requirement, we anticipated that career prospects would be 


\section{American Journal of Pharmaceutical Education 2021; 85 (4) Article 8369.}

a focus for this sample. In addition, students may have sought to study both for the end of year examinations and to retain their clinical knowledge as they move into the health care workforce. Similar to the "social" priority suggested by Byrne, a priority for these students was "friends/relationships." 17 Some may consider that friends and social life are too interrelated to be separated. However, students frequently listed friends/relationships and social life separately in their life priorities, indicating that they saw these as discrete entities. This may reflect differences in how newer generations perceive and act with respect to socialization.

Findings indicated that the student sample focused on some areas of life that were not anticipated. Personal growth was one of the top eight priorities identified in this study. Millennial generations are known to greatly embrace the concepts of self-improvement and self-care. ${ }^{20}$ For example, nursing students have increasingly reported the need for self-care as a priority for personal growth and success. ${ }^{21}$ Mental health/wellbeing was also alluded to more frequently than anticipated. Mental health is becoming less stigmatized with time, and as a result, people may be more aware of mental health needs and comfortable talking about such issues. Interestingly, mental health/wellbeing was commonly highlighted in addition to "health," suggesting that students prioritize these as two separate entities.

A key finding from the analysis using anti-goals was that students valued preparation and the idea of being present as ways to avoid resilience depletion. More specifically, it was found that students focused on aspects of their life that could easily be changed rather than on aspects that would require making long-term adjustments. The use of preparation strategies such as meal prepping, setting alarms, and agendas/task lists were valued by students as methods to avoid resilience depletion. Similarly, strategies such as calling family and making time for friends and relationships may allow students to be present in their daily life and focus on achieving balance within their greater priority areas. Interestingly, antigoals were not found to be greatly associated with life priority areas ( $22.1 \%$ categorized as "other"). A possible explanation is that students worked towards achieving life-balance by focusing on specific skills that relate to multiple priorities (eg, general organization) in order to be more prepared and present within each larger priority area.

This study has implications for development of student support services. Institutions should be aware that students' priorities may be changing, with increasing emphasis on self-development and mental health/wellbeing. Initiatives should be designed to support students within these priorities to help them achieve a better overall sense of life-balance. Self-development could be related to preparation for career opportunities, for example, and mental health/wellbeing could include curricular interventions related to self-care and resilience. Doing so may reduce/alleviate stress and help students achieve balance within these priority areas. Developing sessions that introduce students to tools that build and maintain resilience may positively affect their short and long-term wellbeing. This study also has implications for future research. Studies should be designed across multiple settings with different groups of students to further refine priority areas and better understand how millennial and post-millennial students perceive life-balance. Studies need to evaluate the effectiveness of student support services and seek to identify the most useful interventions to support newer generations of students.

The results of this study need to be viewed in the context of some limitations. First, some priorities may have been underrepresented, as during data analysis, some students listed multiple priorities (eg, gym, running) that were combined into one category (eg, fitness). However, the frequency of this occurrence was small, and we believe data were largely representative of priority areas. Second, some students may have used the given examples as priority areas for the Wheel of Life activity if they could not think of eight themselves. This may have overrepresented some categories, such as personal growth. Finally, the results of this study may not be generalizable to pharmacy student cohorts in other areas of the world. For example, pharmacy students in other areas may enter the program with pre-existing degrees or work experience, which is less common in Aotearoa, New Zealand. Being in a different stage of life, their priority areas and anti-goals may look different than those of the students sampled in this study. Finally, there are likely to be ethnic influences in priority areas for the Wheel of Life and anti-goals, which were not explored in this study. Despite these limitations, findings from this study offer valuable insight into students' life priorities and the ways in which they seek to avoid resilience depletion.

\section{CONCLUSION}

This study investigated how pharmacy students attempt to achieve an overall sense of life-balance by identifying priority areas and specific ways in which they avoid resilience depletion. Findings suggest priority areas may change over time, which aligns with previous work. ${ }^{17}$ Findings also suggest that the concepts of being prepared and being present may help students avoid resilience depletion and may contribute positively to their overall sense of life-balance. These findings support the notion that when 


\section{American Journal of Pharmaceutical Education 2021; 85 (4) Article 8369.}

developing student support mechanisms, educators must take generational change into account and focus efforts on developing services and tools that assist students with being prepared for (and present in) daily activities. Doing so may result in positive outcomes with respect to students' lifebalance and wellbeing.

\section{ACKNOWLEDGMENTS}

The authors acknowledge Charlotte Coard for assistance with the design of Figure 1.

\section{REFERENCES}

1. Marshall LL, Allison A, Nykamp D, Lanke S. Perceived stress and quality of life among doctor of pharmacy students. Am J Pharm Educ. 2008;72(6): 137.

2. Frick LJ, Frick JL, Coffman RE, Dey S. Student stress in a threeyear doctor of pharmacy program using a mastery learning educational model. Am J Pharm Educ. 2011;75(4):Article 64. 3. Gallagher CT, Mehta AN, Selvan R, et al. Perceived stress levels among undergraduate pharmacy students in the UK. Curr Pharm Teach Learn. 2014;6(3):437-441.

4. Labrague LJ, McEnroe-Petitte DM, Gloe D, Thomas L, Papathanasiou IV, Tsaras K. A literature review on stress and coping strategies in nursing students. J Ment Health. 2017;26(5):471-480.

5. Opoku-Acheampong A, Kretchy IA, Acheampong F, et al. Perceived stress and quality of life of pharmacy students in University of Ghana. BMC Res Notes. 2017;10(1):115.

6. Esan O, Esan A, Folasire A, Oluwajulugbe P. Mental health and wellbeing of medical students in Nigeria: a systematic review. Int Rev Psychiatry. 2019;31(7-8):661-672.

7. Farrell SM, Kadhum M, Lewis T, Singh G, Penzenstadler L, Molodynski A. Wellbeing and burnout amongst medical students in England. Int Rev Psychiatry. 2019;31(7-8):579-583.

8. Farrell SM, Molodynski A, Cohen D, et al. Wellbeing and burnout among medical students in Wales. Int Rev Psychiatry. 2019;31(7-8): 613-618.
9. Jiménez-Ortiz JL, Islas-Valle RM, Jiménez-Ortiz JD, PérezLizárraga E, Hernández-García ME, González-Salazar F. Emotional exhaustion, burnout, and perceived stress in dental students. $J$ Int Med Res. 2019;47(9):4251-4259.

10. Sun SH, Zoriah A. Assessing stress among undergraduate pharmacy students in University of Malaya. Indian J Pharm Educ. 2015;49(2):99-105.

11. Hirsch JD, Do AH, Hollenbach KA, Manoguerra AS, Adler DS. 2009. Students' health-related quality of life across the preclinical pharmacy curriculum. Am J Pharm Educ. 2009;73(8):147.

12. Gallagher CT, Mehta AN, Selvan R, et al. Perceived stress levels among undergraduate pharmacy students in the UK. Curr Pharm Teach Learn. 2014;6(3):437-441.

13. Silva RG, Figueiredo-Braga M. Evaluation of the relationships among happiness, stress, anxiety, and depression in pharmacy students. Curr Pharm Teach Learn. 2018;10(7):903-910. 14. Sabourin AA, Prater JC, Mason NA. Assessment of mental health in doctor of pharmacy students. Curr Pharm Teach Learn. 2019;11(3):243-250.

15. Walter G, Soh NL, Norgren Jaconelli S, Lampe L, Malhi GS, Hunt G. Medical students' subjective ratings of stress levels and awareness of student support services about mental health. Postgrad Med J. 2013;89(1052):311-315.

16. Vogan CL, McKimm J, Da Silva AL, Grant A. Twelve tips for providing effective student support in undergraduate medical education. Med Teach. 2014;36(6):480-485.

17. Byrne U. Wheel of Life: Effective steps for stress management. Bus Info Rev. 2005;22(2):123-130.

18. Wilkinson A. 2017. The Power of Anti-Goals. Accessed April 1, 2021. https://medium.com/@awilkinson/the-power-of-anti-goalsc38f5f46d23c.

19. Braun V, Clarke V. Using thematic analysis in psychology. Qual Res Psychol. 2006;3(2):77-101.

20. Trehu J. The shaky foundations of millennials' basic human needs. Society. 2017;54:533-534.

21. Gardner EA, Deloney LA, Grando VT. Nursing student descriptions that suggest changes for the classroom and reveal improvements needed in study skills and self-care. J Prof Nurs. 2007; 23(2):98-104. 